\title{
Adsorption of U(VI) onto Amidoxime-functionalized Hydrothermal Carbon in the Presence of $\mathrm{Ca}-\mathrm{U}(\mathrm{VI})-\mathrm{CO}_{3}$ Complexes
}

\author{
Yinghui XIE, Zhimmin DONG, Haoyan ZHANG, Runze ZHOU, Yunhai LIU, Zhibin ZHANG*
}

State Key Laboratory of Nuclear Resources and Environment, East China University of Technology, Nanchang, Jiangxi, China,330013

*Corresponding Author: Zhibin ZHANG, ate Key Laboratory of Nuclear Resources and Environment, East China University of Technology, Nanchang, Jiangxi, China

\begin{abstract}
:
The aim is collecting uranium from groundwater in which uranium mainly exists in negative species, the amidoxime-functionalized hydrothermal carbon (AO-HTC) was synthesized. From the results of $\mathrm{N}_{2}$ adsorption-desorption and SEM, AO-HTC is a small spherical surface; FT-IR and Elemental analysis showed that the amidoxime group was successfully grafted onto the surface of the material; Zeta-potential measurement showed that the amino nitrogen atom is protonated in the oxime group. The optimum $\mathrm{pH}$ value of AO-HTC for uranium adsorption is 6.0, and the adsorption equilibrium is reached within 80 min, which is in accordance with the pseudo-second order adsorption kinetic model. The adsorption of uranium by AO-HTC accords with the Langmuir isotherm adsorption model, and the single-layer saturated adsorption capacity is $254.13 \mathrm{mg} \bullet \mathrm{g}^{-1}$. The thermodynamic parameters calculated by the adsorption isotherm indicate that AO-HTC adsorption of uranium is a spontaneous endothermic chemical process and Carbonate ion, calcium ion and humic acid concentration have great influence on uranium adsorption. The experiments results show that AO-HTC has the potential to elimination of U(VI) from groundwater.

Keywords: uranium; amidoxime; hydrothermal carbon; adsorption; $\mathrm{Ca}-\mathrm{U}(\mathrm{VI})-\mathrm{CO}_{3}$ complexes
\end{abstract}

\section{Introduction}

Nowadays, the soil has been polluted to varying degrees around the uranium smelter and the tailings pond, causing serious damage to the surrounding environment, and the groundwater has been seriously threatened with the migration of nuclide in the soil ${ }^{[1,2]}$. Groundwater is an important resource for human being survival, it is a limited ecological resource that only accounts for a small part of the total water resources. The contribution of groundwater is crucial perhaps as many as 2 billion people rely directly on aquifers for drinking water ${ }^{[3]}$. In China, some of the regions like arid zones of Northwest China are entirely dependent on groundwater ${ }^{[4]}$. If it is not well managed, groundwater resources are highly vulnerable to widespread pollution.

There are some differences in the presence of uranium under aerobic and anaerobic condition $s^{[5]}$. Under aerobic conditions, uranium mainly exists in the oxidation state of $\mathrm{U}(\mathrm{VI})$. For example, uranium form is $\mathrm{UO}_{2}^{2+}$ (uranyl) in acidic water with $\mathrm{pH}<2.5$. Under anaerobic conditions, $\mathrm{U}(\mathrm{VI})$ is easily reduced to insoluble $\mathrm{U}(\mathrm{IV})$, and the solubility of the reduced state is only one ten-thousandth of the oxidation state ${ }^{[6]}$. Therefore, the reduced state U(IV) is not easy to migrate in the environment, the pollution source is not easily diffused, and as not as possible widespread contamination. The existence of $\mathrm{U}(\mathrm{VI})$ in soil and groundwater is the key point of current research ${ }^{[7]}$.

The difference in morphology is the main reason for the low removal efficiency. In the complex natural environment, many factors affect the morphology of uranium, mainly two points. First, soluble organic carbon, which is mainly humic acid in soil and groundwater, humic acid is one a mixture rich in oxygen-containing functional groups (hydroxyl, carboxyl, etc.). humic acid reacts with $\mathrm{U}(\mathrm{VI})$ to form soluble salt in natural water (alkaline), thus changing the existing form of uranium. In groundwater, uranium does not precipitate with anions such as $\left(\mathrm{UO}_{2}\right)_{2}(\mathrm{OH})_{2}{ }^{2+}$, but one or several soluble complexes ions are easy to migrate such as $\mathrm{UO}_{2}\left(\mathrm{CO}_{3}\right)_{2}{ }^{2-}, \mathrm{UO}_{2}\left(\mathrm{CO}_{3}\right)_{3}^{4-}$, $\mathrm{UO}_{2} \mathrm{CO}_{3}$ (aq), etc ${ }^{[8-10]}$. Second, calcium and alkaline earth metal ions in the environment, rocks and soil rich in carbonate minerals, after the erosion of rainwater and river water, some carbonate minerals will be washed into small particles, the surface portion will dissolve at the same time $^{[11]}$. Therefore, natural water contains a certain amount 
of alkaline earth metal ions such as $\mathrm{Ca}^{2+}$ and $\mathrm{Mg}^{2+}$. The $\mathrm{pH}$ of water in nature is close to neutral, which is conducive to the dissolution of carbon dioxide gas in the air, further increasing the concentration of carbonate ions in water ${ }^{[12,}$ ${ }^{13]}$. It has been reported that the main forms of uranium are $\mathrm{Ca}_{2} \mathrm{UO}_{2}\left(\mathrm{CO}_{3}\right)_{3}(\mathrm{aq}), \mathrm{CaUO}_{2}\left(\mathrm{CO}_{3}\right)^{2-}$ and $\left.\mathrm{MgUO}_{2}\left(\mathrm{CO}_{3}\right)_{3}\right)^{2-}$ in the natural waters ${ }^{[14]}$.

The form of uranium in soil or groundwater (such as $\quad \mathrm{UO}_{2}\left(\mathrm{CO}_{3}\right)_{2}{ }^{2-}, \quad \mathrm{UO}_{2}\left(\mathrm{CO}_{3}\right)_{3}{ }^{4-}, \quad \mathrm{UO}_{2} \mathrm{CO}_{3}(\mathrm{aq})$ $\mathrm{Ca}_{2} \mathrm{UO}_{2}\left(\mathrm{CO}_{3}\right)_{3}$ (aq) and $\mathrm{CaUO}_{2}\left(\mathrm{CO}_{3}\right)^{2-}$, etc.) is similar to that in seawater $\left(\mathrm{UO}_{2}\left(\mathrm{CO}_{3}\right)_{3}^{4-}, \mathrm{CaUO}_{2}\left(\mathrm{CO}_{3}\right)^{2-}\right.$ and $\mathrm{MgUO}_{2}\left(\mathrm{CO}_{3}\right)_{3}^{2-}$, etc. $)^{[15,16]}$. The terrible ability to identify interacting species of oxygen-containing functional group, which limits the application of HTC functional materials in certain fields. However, the amidoxime group has attracted much attention for the high chelation affinity and selectivity of uranium by the reaction of nitrile groups with hydroxylamine, which has been supported on various materials (such as polymeric fibers, porous polymers, metal organic framework) exhibit superiority to uranium adsorption ${ }^{[17,18]}$. In groundwater, uranyl was contacted with amidoxime in the form of $\mathrm{UO}_{2}\left(\mathrm{CO}_{3}\right)_{2}{ }^{2-}$ or $\mathrm{UO}_{2}\left(\mathrm{CO}_{3}\right)_{3}{ }^{4-}$, and then the chelating uranyl was coordinated with amidoxime group and absorbed by the amidoxime-based adsorbent ${ }^{[19}$, 20]. Therefore, the feasibility and abundance of amidoxime are two key points determining the adsorption capacity of uranium.

In this work, an amidoxime functionalized hydrothermal carbon adsorption material was prepared as an adsorbent for treatment of uranium-containing groundwater. The amidoxime group can be obtained by reduction of a nitrile group, and the reaction conditions are were no longer various conventional modification processes. The acrylonitrile can be grafted onto the starch by a polymerization grafting method ${ }^{[21]}$. The grafted starch is further hydrolyzed to obtain a nitrile-grafted hydrothermal carbon intermediate. Finally, the nitrile group is reduced to an amidoxime group in a hydroxylamine hydrochloride solution to obtain a desired hydrothermal carbon adsorbent. The effects of amidoxime-functionalized hydrothermal carbon adsorbent on the removal of uranium from water were studied by batch experiments. The effects of $\mathrm{pH}$ value, carbonate, calcium and humic acid content on the removal efficiency were investigated.
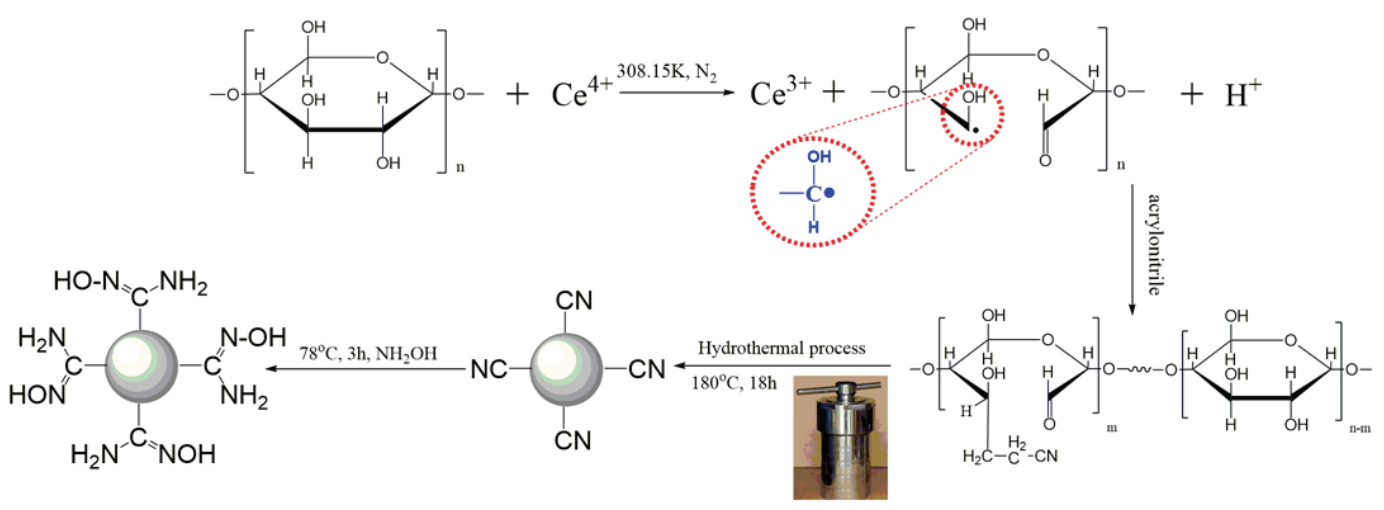

Scheme 1. Schematic of processes for AO-HTC

\section{Experimental}

\subsection{Synthesis of amidoxime-functionalized hydrother-} mal carbon (AO-HTC)

The preparation process of AO-HTC is shown in Scheme 1. Generally, $10 \mathrm{~g}$ soluble starch was dissolved in $100 \mathrm{~mL}$ of deionized water, then, the reaction system was heated at $35^{\circ} \mathrm{C}$ for $2 \mathrm{~h}$ and stirred under a nitrogen atmosphere, added to ceric ammonium nitrate solution to react for 30 $\min , 2 \mathrm{~mL}$ acrylonitrile was added into and reacted 80 ${ }^{\circ} \mathrm{C}$ for $2 \mathrm{~h}$. It was observed that the starch remained solid and not gelatinized, the product was washed 3 times with absolute ethanol, and finally the product was washed twice with deionized water and dried. An acrylonitrile grafted starch (AN-Starch) was obtained. The prepared $6.67 \mathrm{~g}$ of AN-starch was dissolved in $50 \mathrm{~mL}$ of distilled water, uniformly stirred for $30 \mathrm{~min}$, and then transferred to a 100 $\mathrm{mL}$ Teflon-lined stainless steel autoclave, followed by heating at $180{ }^{\circ} \mathrm{C}$ for $18 \mathrm{~h}$. The intermediate product was washed thoroughly with deionized water and ethanol, and then dried in a vacuum oven at $60{ }^{\circ} \mathrm{C}$ for 24 hours. Finally, $1.0 \mathrm{~g}$ intermediate product was added to $40 \mathrm{~mL}$ of $40 \mathrm{~g} \cdot \mathrm{L}^{-1}$ hydroxylamine hydrochloride solution and stirred at $78{ }^{\circ} \mathrm{C}$ for $3 \mathrm{~h}$. Then, the mixture was filtered; the resultant was thoroughly washed with deionized water and ethanol, and then dried under vacuum at $60{ }^{\circ} \mathrm{C}$ overnight.

\subsection{Results and discussion Characterization}

\section{SEM}

The scanning electron microscope was used to characterize the micro-morphology and particle size of carbon microspheres. The images of the as-synthesized samples displayed in Fig. 1(a) clearly show that large number of spherical nanoparticles after hydrothermal carbonization, moreover, the surface is regular, and no significant morphological change is observed for AO-HTC and the particle size of the AO-HTC is in the range of about 2 to $7 \mu \mathrm{m}$. It is found in that the AO-HTC particles are decentralized with each other.

FT-IR

The FT-IR spectra were analyzed to investigate the surface 
functional groups of AO-HTC (Fig. 1(b)). The AO-HTC shows the common stretching bands at 1604 and 3248 $\mathrm{cm}^{-1}$, which are associated with $\mathrm{C}=\mathrm{O}$ carboxylate and $\mathrm{O}-\mathrm{H}$ groups, respectively ${ }^{[22]}$. After being modified with $\mathrm{AO}$, three peaks appear at $1631 \mathrm{~cm}^{-1}, 1272 \mathrm{~cm}^{-1}$ and 927 $\mathrm{cm}^{-1}$, belonging to $\mathrm{C}=\mathrm{N}$ or $\mathrm{C}=\mathrm{C}, \mathrm{C}-\mathrm{N}$ and $\mathrm{N}-\mathrm{O}$ stretching vibrations, respectively ${ }^{[21]}$. It is clearly indicating that the nitrile group have been converted to the amidoxime group in the presence of hydroxylamine hydrochlorid ${ }^{\text {[23]. }}$

Zeta potential

Fig. 1(c) shows the zeta potential curve of AO-HTC, indicating that the zeta potential of AO-HTC is positive at $\mathrm{pH}<4.76$, due to the protonation of the $\mathrm{N}$ atom of $-\mathrm{NH}_{2}$ in the amidoxime groups, this is favorable for adsorption of positively uranyl ions. Moreover, with the $\mathrm{pH}$ value increasing, the potential of the AO-HTC becomes negative value, the reason is that the deprotonation of $-\mathrm{NH}_{2}$ in the amidoxime groups and increased the dissociation of oxime hydroxyl groups ${ }^{[24]}$. After $\mathrm{pH}>4.76$, due to the deprotonation of the amidoxime group, the dissociation of the oxime hydroxyl group is increase, and the zeta potential of the AO-HTC becomes negative, which is favorable for binding to the positive radionuclide ion. Moreover, the point of zero charges of AO-HTC was $4.76 \mathrm{mV}$, which is beneficial to reduce the surface of AO-HTC adsorbent Electrostatic repulsion of uranium in solution. The property of the amidoxime group is of great importance for the removal of uranium in the environment.

N2-BET

The $\mathrm{N}_{2}$ adsorption-desorption isotherm and pore size distribution of AO-HTC are shown in Fig. 1(d) and Table 1. It can be observed that type IV isotherm curves with
$\mathrm{H}_{2}$ hysteresis loops at relative pressures $\left(\mathrm{P} / \mathrm{P}_{0}=0.5\right)$, which is typical for mesoporous structures and also indicates that the mesostructure of AO-HTC. However, the average pore diameter was $7.93 \mathrm{~nm}$ indicating that the polyacrylamidoxime groups distribution on the surface of the material and limited the pore size. This amidoxime surface of the AO-HTC was good for binding the uranium and allowing the uranium to adsorb on the adsorption sites on the surface of the material.

Table 1. Structural and textural properties of AO-HTC.

\begin{tabular}{cccc}
\hline Material & $\begin{array}{c}\text { Surface } \\
\text { area SBET } \\
\left(\mathrm{m}^{2} \cdot \mathrm{g}^{-1}\right)\end{array}$ & $\begin{array}{c}\text { Pore volume } \\
\left(\mathrm{cm}^{3} \cdot \mathrm{g}^{-1}\right)\end{array}$ & $\begin{array}{c}\text { Average pore } \\
\text { diameter }(\mathrm{nm})\end{array}$ \\
\hline AO-HTC & 2.75 & 0.02 & 7.93 \\
\hline
\end{tabular}

\subsection{Elemental analysis}

Elemental analysis was used to calculate the exact number of amidoxime group in AO-HTC. Table 2 shows the content of carbon, nitrogen and hydrogen by modifying HTC, the nitrogen content of AO-HTC is $7.15 \%$, indicating that the amidoxime group is grafted onto the surface of the HTC, as supporting by the previous FT- IR. The number of amidoxime group was calculated to be about $2.55 \mathrm{mmol} \cdot \mathrm{g}^{-1}$ based on the increase in nitrogen content.

Table 2. The element analysis of AO-HTC.

\begin{tabular}{cccc}
\hline Samples & $\mathrm{C} \%$ & $\mathrm{H} \%$ & $\mathrm{~N} \%$ \\
\hline AO-HTC & 50.82 & 4.62 & 7.15 \\
\hline
\end{tabular}

(b)
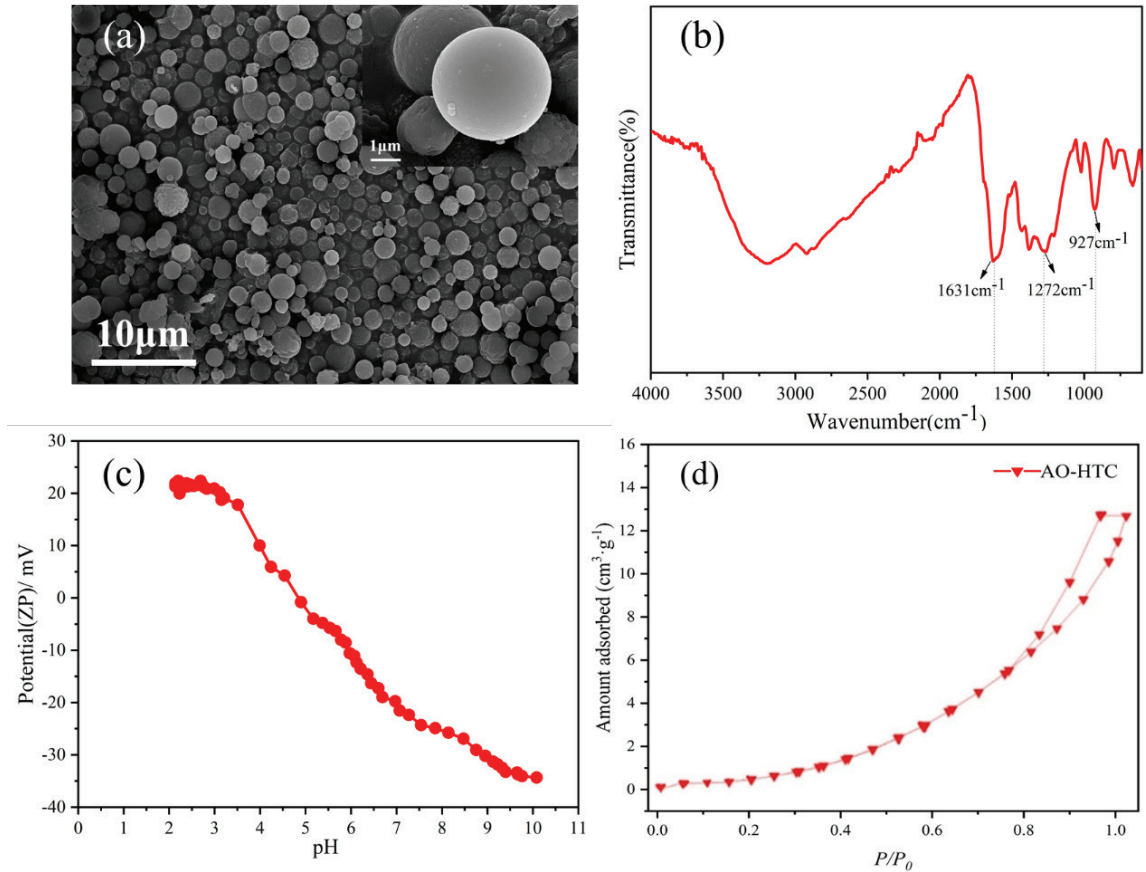

Figure 1. SEM images of AO-HTC (a), FT-IR spectra of AO-HTC ( b), Zeta potentials of AO-HTC as a function of pH (c), Nitrogen adsorption-desorption isotherms and pore-size distribution for AO-HTC (d). 


\subsection{Batch sorption experiments}

Effect of $p H$

The $\mathrm{pH}$ was regard as one of the most important environmental factors effect the speciation of uranium ions $^{[25]}$. The influence of $\mathrm{pH}$ on the adsorption among AOHTC and uranium ions was displayed in Fig. 2(a). With the increase of $\mathrm{pH}$, the adsorption capacity of $\mathrm{U}(\mathrm{VI})$ was increased on AO-HTC, the maximum adsorption capacity was $254.13 \mathrm{mg} \cdot \mathrm{g}^{-1}$ at $\mathrm{pH}=6.0$, it can be seen that the adsorption capacity of AO-HTC was better than other situations. Comparison of U(VI) adsorption of AO-HTC with other related adsorbents is listed in table 3. The AOHTC has excellent performance under different adsorption conditions, which indicates that AO-HTC is an excellent choice for actual environmental pollution groundwater. $\mathrm{U}(\mathrm{VI})$ was mainly present in the form of $\mathrm{UO}_{2}{ }^{2+}$ in this absorption reaction. The morphological distribution of uranium (VI) was simulated by Visual MINTEQ 3.1, as shown in Fig. 2(b), the morphology of uranium (VI) is $\mathrm{UO}_{2}{ }^{2+}, \mathrm{UO}_{2} \mathrm{OH}^{+}$and $\left(\mathrm{UO}_{2}\right) \mathrm{CO}_{3}(\mathrm{aq})$ at $3.0<\mathrm{pH}<5.0$ and $\mathrm{Ca}_{2}\left(\mathrm{UO}_{2}\right)\left(\mathrm{CO}_{3}\right)_{2}(\mathrm{aq}), \mathrm{Ca}\left(\mathrm{UO}_{2}\right)\left(\mathrm{CO}_{3}\right)_{3}{ }^{2-}$ at $\mathrm{pH}>6$, combined with the Zeta potential, the calcium-uranium-carbonate complex $\mathrm{Ca}_{2} \mathrm{UO}_{2}\left(\mathrm{CO}_{3}\right)_{3}$ and $\mathrm{UO}_{2}\left(\mathrm{CO}_{3}\right)_{3}{ }^{2-}$ are increasing with $\mathrm{pH}$, the amount of positively charged uranyl ion species gradually decreases, Which have a great influence for adsorption of uranium (VI).

\subsection{Effect of carbonate}

Uranium is usually present in the natural water environment as the form of uranyl carbonate, because uranium carbonate is a strong ligand ${ }^{[34]}$. The effect of carbonate ions on the adsorption of uranium by AO-HTC was shown in Fig. 2(c). The adsorption capacity of AO-HTC for uranium gradually decreased from $214.54 \mathrm{mg} \cdot \mathrm{g}^{-1}$ to $103.32 \mathrm{mg} \cdot \mathrm{g}^{-1}$ by increasing the carbonate ion concentration. It is observed from Fig. 2(d) that the carbonate concentration increased from 0 to $4.0 \mathrm{mmol} \cdot \mathrm{L}^{-1}$, the ions such as $\left(\mathrm{UO}_{2}\right)_{3}(\mathrm{OH})_{5}^{+}$, $\mathrm{UO}_{2}^{2+}$ and $\left(\mathrm{UO}_{2}\right)_{4}(\mathrm{OH})^{7+}$ decreased to an extremely low level and neutral $\mathrm{Ca}_{2} \mathrm{UO}_{2}\left(\mathrm{CO}_{3}\right)_{3}$ (aq) and negative $\left(\mathrm{UO}_{2}\right)_{2} \mathrm{CO}_{3}(\mathrm{OH})_{3}{ }^{-}, \mathrm{CaUO}_{2}\left(\mathrm{CO}_{3}\right)_{3}{ }^{2-}$ species were obviously increased. In addition, the increase of the concentration of carbonate ions was lead to decrease potential value on the surface of the AO-HTC, and the formation of electrostatic repulsion between the uranium-carbonate and calciumuranium-carbonate complex anions, which will impact the adsorption of uranium in the solution by the material, further reducing the AO-HTC adsorption capacity.

\subsection{Effect of calcium}

Calcium plays a key role in the adsorption of uranium in groundwater, Which forming a dikaryon or multikaryon complex such as $\mathrm{Ca}_{2} \mathrm{UO}_{2}\left(\mathrm{CO}_{3}\right)_{3}(\mathrm{aq})$ and $\mathrm{CaUO}_{2}\left(\mathrm{CO}_{3}\right)_{3}{ }^{2-}$ [35]. The effect of calcium ions on the adsorption of uranium by AO-HTC was shown in Fig. 2(e). With the increasing of calcium ions concentration, the adsorption capacity of AO-HTC to uranium gradually decreased from the original $201.34 \mathrm{mg} \cdot \mathrm{g}^{-1}$ to $107.12 \mathrm{mg} \cdot \mathrm{g}^{-1}$. Combined with the distribution pattern of uranyl ions in the aqueous phase, the morphological distribution at different calcium concentrations was calculated by Visual MINTEQ 3.1 software as shown in Fig. 2(f). With the increase of $\mathrm{Ca}^{2+}$ concentration from 0 to $2.0 \mathrm{mmol} \cdot \mathrm{L}^{-1}$, the negatively charged $\mathrm{UO}_{2}\left(\mathrm{CO}_{3}\right)_{3}^{4-}, \mathrm{UO}_{2}\left(\mathrm{CO}_{3}\right)_{2}^{2-}$ and $\left(\mathrm{UO}_{2}\right)_{2} \mathrm{CO}_{3}(\mathrm{OH})_{3}$ were almost disappeared, which are forming a calciumuranium-carbonate complex $\mathrm{Ca}_{2} \mathrm{UO}_{2}\left(\mathrm{CO}_{3}\right)_{3}$ and $\mathrm{CaUO}_{2}\left(\mathrm{CO}_{3}\right)_{3}{ }^{2-}$ that declined the ability of materials to adsorb uranium.

Table 3. Comparison of adsorption capacities of various adsorbents for uranium(VI)

\begin{tabular}{cccc}
\hline Sorbents & $\begin{array}{c}\text { Experimental con- } \\
\text { ditions }\end{array}$ & $\begin{array}{c}\text { Adsorption capacities } \\
\left(\mathrm{mg}^{-1}\right)\end{array}$ & References \\
\hline Mesoporous Carbon & $\mathrm{PH}=6.5$ & 178.6 & {$[26]$} \\
PANI/CMK-3 & $\mathrm{PH}=6.0$ & 118.3 & {$[28]$} \\
AO-CMK-3 & $\mathrm{PH}=5.0$ & 238.7 & {$[22]$} \\
AO-OMC & $\mathrm{PH}=5.0$ & 322.6 & {$[29]$} \\
Activated Carbon & $\mathrm{pH}=3.0$ & 28.3 & {$[30]$} \\
AO-Polyethylene Fibers & $\mathrm{PH}=4.0$ & 176.1 & {$[31]$} \\
Fe3O4 & $\mathrm{PH}=5.5$ & 228.2 & {$[32]$} \\
CMK-5 & $\mathrm{PH}=4.0$ & 65.4 & {$[26]$} \\
CMK-3-COOH & $\mathrm{PH}=6.5$ & 250.0 & [33] \\
HTC-COOH & $\mathrm{PH}=6.0$ & 205.8 & This Work \\
AO-HTC & $\mathrm{PH}=6.0$ & 254.1 & \\
\hline
\end{tabular}


(a)

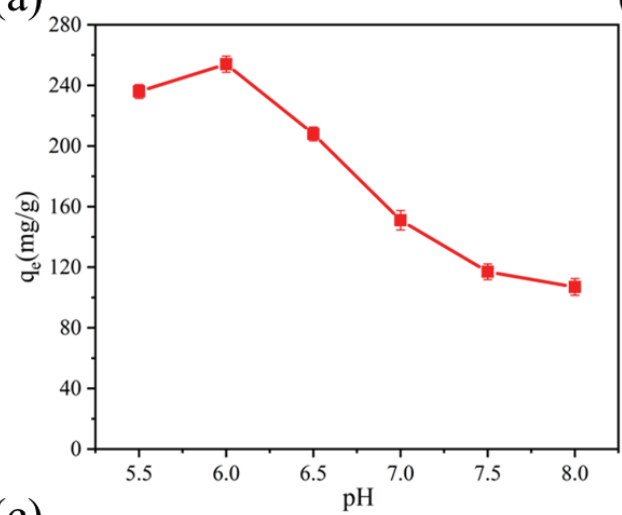

(c)

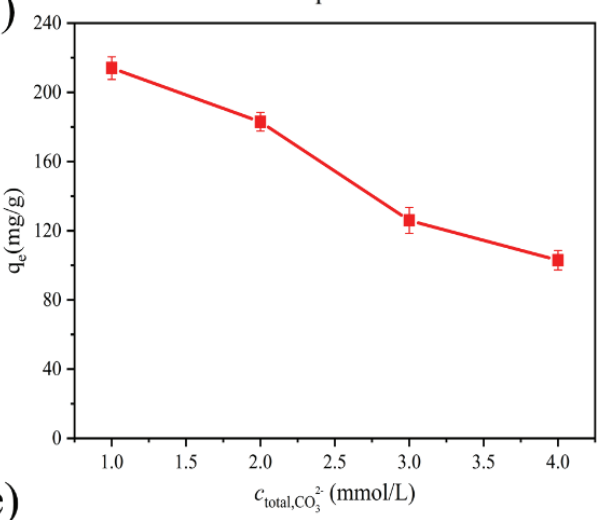

(e)

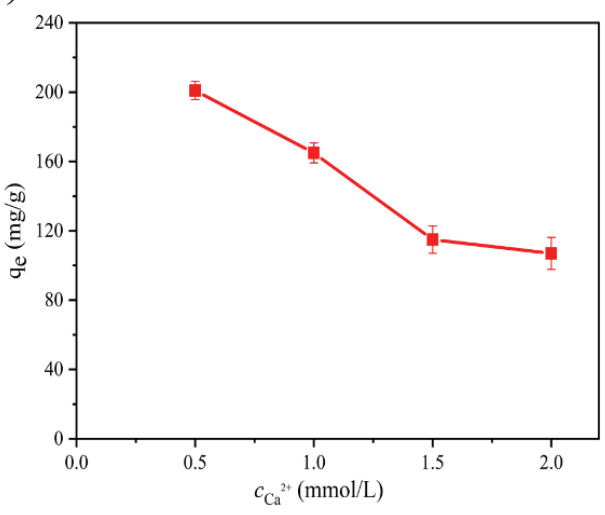

(b)

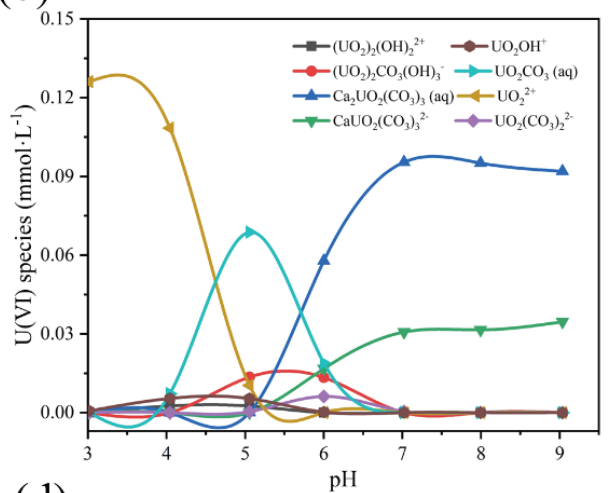

(d)
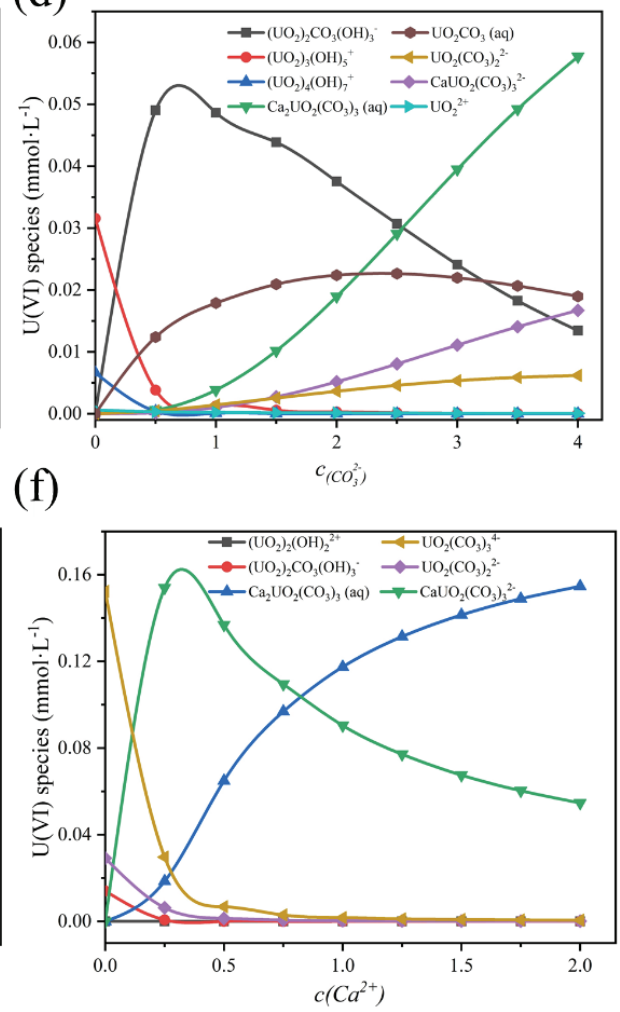

Figure 2. Effect of (a) $\mathrm{pH}$ on the adsorption of uranium on AO-HTC and (b) the distribution of uranium in in different pH solution $\left(C_{0}=50 \mathrm{mg} \cdot \mathrm{L}^{-1}, m=10 \mathrm{mg}, \mathrm{C}\left[\mathrm{Ca}^{2+}\right]=2.0 \mathrm{mmol} \cdot \mathrm{L}^{-1}, \mathrm{C}^{2}\left[\mathrm{CO}_{3}{ }^{2+}\right]=4.0 \mathrm{mmol} \cdot \mathrm{L}^{-1}, t=180 \mathrm{~min}, T=298.15 \mathrm{~K}\right)$, Effect of (c) $\mathrm{CO}_{3}^{2-}$ concentration on the adsorption of uranium on AO-HTC and (d) the distribution of uranium in in different concentration of $\mathrm{CO}_{3}{ }^{2-}$ solution $\left(\mathrm{pH}=6.0, m=10 \mathrm{mg}, \mathrm{C}_{0}=50 \mathrm{mg} \cdot \mathrm{L}^{-1}, \mathrm{C}\left[\mathrm{Ca}^{2+}\right]=2.0 \mathrm{mmol} \cdot \mathrm{L}^{-1}, t=180 \mathrm{~min}, T=\right.$ $298.15 \mathrm{~K}$ ), Effects of (e) $\mathrm{Ca}^{2+}$ concentration on the adsorption of uranium on AO-HTC and (f) the distribution of uranium in different concentration of $\mathrm{Ca}^{2+}$ solution $\left(\mathrm{pH}=6.0, \mathrm{C}_{0}=50 \mathrm{mg} \cdot \mathrm{L}^{-1}, m=10 \mathrm{mg}, \mathrm{C}\left[\mathrm{CO}_{3}{ }^{2-}\right]=4.0 \mathrm{mmol} \cdot \mathrm{L}^{-1}, t=180 \mathrm{~min}, T\right.$ $=298.15 \mathrm{~K})$

\subsection{Effect of humic acid}

Humic acid has a strong affinity for environmental substances in various natural water systems, which possibly have an impact on uranium adsorption ${ }^{[36,37]}$. The effect of humic acid on the adsorption of uranium by AO-HTC is shown in Fig. 3(a). The adsorption capacity of AO-HTC for uranium decreased from $109.92 \mathrm{mg} \cdot \mathrm{g}^{-1}$ to $39.78 \mathrm{mg} \cdot \mathrm{g}^{-1}$ with the increase of humic acid concentration. The reason is that humic acid is rich in affinity of adsorption groups such as carbonyl, carboxyl, and hydroxyl groups, which can occupy the adsorption sites of the adsorbents, resulting in a decrease in the adsorption amount of uranium. humic acid in the solution easily combines with free uranium to generate a U(VI)-humic acid complex, which has a tight colloidal structure and is not easily adsorbed by AO-HTC ${ }^{[17]}$. Meanwhile, humic acid will compete with uranium to adsorb on the surface of AO-HTC ${ }^{[38]}$. The adsorbed humic acid is not easy to combine with uranium in the solution, further reducing the adsorption of uranium on AO-HTC. 

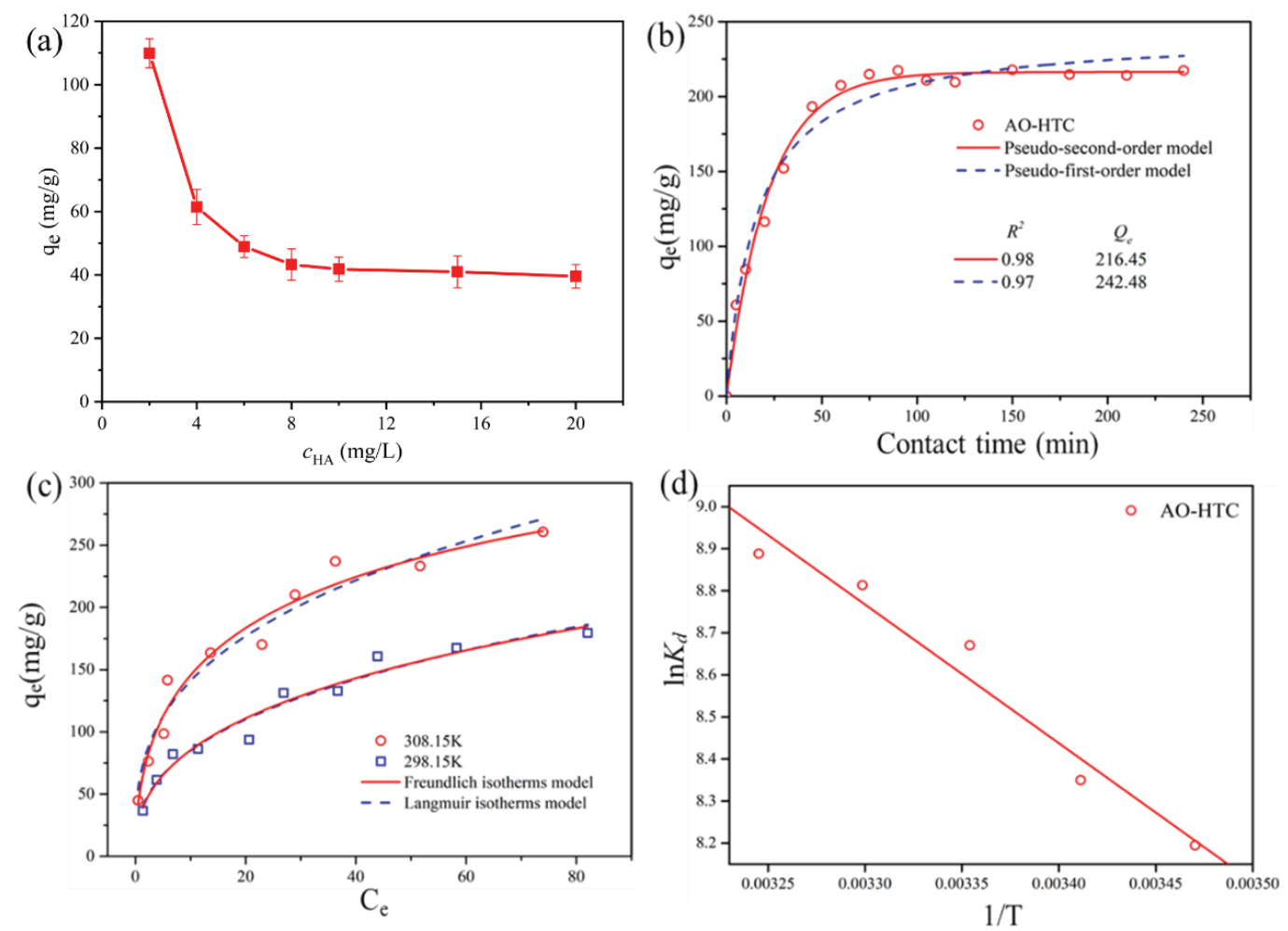

Figure 3. (a) Effects of humic acid concentration on the uranium adsorption on AO-HTC $\left(C_{0}=50 \mathrm{mg} \cdot \mathrm{L}^{-1}, \mathrm{~m}=10 \mathrm{mg}\right.$, $\left.\mathrm{C}\left[\mathrm{Ca}^{2+}\right]=2.0 \mathrm{mmol} \cdot \mathrm{L}^{-1}, \mathrm{C}\left[\mathrm{CO}_{3}^{2+}\right]=4.0 \mathrm{mmol} \cdot \mathrm{L}^{-1}, t=180 \mathrm{~min}, T=298.15 \mathrm{~K}\right)$. (b) The adsorption kinetics of U(VI) on AOHTC $\left(C_{0}=50 \mathrm{mg} \cdot \mathrm{L}^{-1}, m=10 \mathrm{mg}, \mathrm{pH}=6.0, T=298.15 \mathrm{~K}\right)$. (c) The adsorption isotherms of U(VI) on AO-HTC at 298.15 $\mathrm{K}$ and $308.15 \mathrm{~K}(\mathrm{pH}=6.0, m=10 \mathrm{mg}, t=180 \mathrm{~min}, T=298.15 \mathrm{~K})$. (d) The thermodynamic fitting $\left(C_{0}=50 \mathrm{mg} \cdot \mathrm{L}^{-1}, m=10\right.$ $\mathrm{mg}, \mathrm{pH}=6.0, t=180 \mathrm{~min})$

\subsection{Kinetic studies}

The contact time has a great influence on the mass transfer rate of metal ions in aqueous solution. The result shown in Fig. 3(b), it is seen that the adsorption quantity of AO-HTC increases with the contact time, and reaches the adsorption equilibrium at $80 \mathrm{~min}$. When the equilibrium time is exceeded, since the active site on the surface of the adsorbent material has been occupied, the amount of adsorption no longer changes significantly. It was attributed to the synergy of the rich oxygen-containing functional groups with the $\mathrm{C}-\mathrm{N}$ bond, providing sufficient active sites for the immobilization and binding of $U(V I)$.

The contact time can reflect adsorption kinetics, and the experimental data can be used to calculate whether the pseudo-first-order and pseudo-second-order kinetic equations are analyze the adsorption process. ${ }^{[39,40]}$, which were exhibited as follows:

$\ln \left(q_{e}-q_{t}\right)=\ln q_{e}-k_{1} t$

$$
\frac{\mathrm{t}}{\mathrm{q}_{\mathrm{t}}}=\frac{1}{k_{2} q_{e}^{2}}+\frac{t}{q_{e}}
$$

Where $q_{e}$ and $q_{t}$ were the amounts of absorbed U(VI) after equilibrium at a time " $\mathrm{t}$ ", $\mathrm{k}_{1}$ and $\mathrm{k}_{2}$ were the constant for the pseudo-first-order and pseudo-second-order kinetic rat, respectively. These values can be obtained from the linear graph of $\ln \left(q_{e}-q_{t}\right)$ vs $t$ as shown in Fig. 3(b), and these parameters were tabulated in table 4 . The higher correlation coefficient indicated that the adsorption kinetics of U(VI) on AO-HTC fitted well with the pseudo-second-order kinetic model. Meanwhile, the theoretical calculated $q_{2}$ (234.74 $\left.\mathrm{mg} \cdot \mathrm{g}^{-1}\right)$ of the pseudo-second-order kinetic model is very close to the experimental $q_{e}\left(207.06 \mathrm{mg} \cdot \mathrm{g}^{-1}\right)$ at $298.15 \mathrm{~K}$. Therefore, adsorption behavior was mainly controlled by chemical reaction rather than physical process. In addition, this is also based on the assumption that the rate-limiting step may be chemical adsorption, involving valence electron forces through electron sharing or exchange between the surface groups of AO-HTC and uranium.

Table 4. Parameters for Kinetic models of U(VI) adsorption by AO-HTC and HTC

\begin{tabular}{cccccccc}
\hline Absorbent & $\begin{array}{c}q_{e, e x p} \\
\left(\mathrm{mg}^{-1}\right)\end{array}$ & $\begin{array}{c}q_{1, \text { cal }} \\
\left(\mathrm{mg}^{-1}\right)\end{array}$ & $\begin{array}{c}k_{1} \\
\left(\mathrm{~min}^{-1}\right)\end{array}$ & $R^{2}$ & $\begin{array}{c}q_{2, \text { cal }} \\
\left(\mathrm{mg}^{-1}\right)\end{array}$ & $\begin{array}{c}k_{2} \\
\left(\mathrm{~g} \cdot \mathrm{mg}^{-1} \cdot \mathrm{min}^{-1}\right)\end{array}$ & $R^{2}$ \\
\hline HTC & 50.02 & 17.97 & $1.42 \times 10^{-2}$ & 0.908 & 50.99 & $2.21 \times 10^{-3}$ & 0.997 \\
AO-HTC & 207.06 & 125.22 & $2.75 \times 10^{-2}$ & 0.906 & 234.74 & $2.32 \times 10^{-3}$ & 0.991 \\
\hline
\end{tabular}




\subsection{Adsorption Isotherms Studies}

To explore the adsorption behavior and reaction mechanism of uranium ionic, two typical isotherm models, i.e., the Langmuir isotherm models and Freundlich isotherm models ${ }^{[41]}$, were studied under the condition of $\mathrm{T}=298.15$ $\mathrm{K}$ and $\mathrm{T}=308.15 \mathrm{~K}$. The adsorption isotherms of $\mathrm{U}(\mathrm{VI})$ were shown in Fig. 3(c). It can be seen that the adsorption reacting reach equilibrium rapidly. The adsorption capacity of $\mathrm{U}(\mathrm{VI})$ on AO-HTC was improved with increasing equilibrium concentration of U(VI). Langmuir and Freundlich's models were applied to fit the experimental data and analyze the adsorption mechanism of uranium on AO-HTC. The two adsorption isotherms models were expressed as Eqs. (3) and (4):

$\frac{\mathrm{C}_{\mathrm{e}}}{q_{e}}=\frac{1}{q_{m} k_{L}}+\frac{C_{e}}{q_{m}}$

$\ln q_{e}=\ln K_{F}+\left(\frac{1}{n}\right) \ln C_{e}$

Where $q_{e}$ was regarded as the sorption capacity of $\mathrm{U}(\mathrm{VI})$ on $\mathrm{AO}-\mathrm{HTC}$ at equilibrium time. $\mathrm{K}_{L}$ and $\mathrm{K}_{F}$ considered as constants of Langmuir and Freundlich separately, $\mathrm{n}$ was the factor of Freundlich related to the sorption intensity. $\mathrm{C}_{e}$ was the equilibrium concentration of $\mathrm{U}(\mathrm{VI}), q_{m}$ was the maximum saturated sorption capacity between AO-HTC and uranyl ions.

Langmuir isotherm model used to extensively describe monolayer adsorption which occurs between the homogeneous active sites on the surface of adsorbent and target ions. Freundlich isotherm model assumes a multilayer sorption reaction was present among absorbent with heterogeneous active sits and adsorbate. The relative parameters were obtained from the two isotherms models simulation curves Fig. 3(c) and table 5, which illustrated that the experimental data was fitted the Langmuir isotherm models well $\left(R^{2}>0.99\right)$. Demonstrating the absorption behaver was monolayer sorption process. Compared with HTC, the maximum saturated adsorption capacity of U(VI) on AO-HTC (244.11 mg.g-1) increased significantly. Which was attributed to the enhanced active sits and abundant amidoxime groups were distributed on the surface of HTC.

\subsection{Thermodynamic studies}

The thermodynamic indices were introduced to investigate the effort of temperature on absorption reaction and analysis absorption mechanism. Various thermodynamic parameters i.e., $\Delta S\left(\mathrm{~J} \cdot \mathrm{K}^{-1} \cdot \mathrm{mol}^{-1}\right), \Delta G\left(\mathrm{~kJ} \cdot \mathrm{mol}^{-1}\right)$ and $\Delta H$ $\left(\mathrm{kJ} \cdot \mathrm{mol}^{-1}\right)$, were based on the equations (5)-(6) which were employed to calculate the feasibility of the sorption process $^{[42]}$.

$\ln K_{d}=\frac{\Delta S}{R}-\frac{\Delta H}{\mathrm{RT}}$

$\Delta G=\Delta H-T \Delta S$

Where the $K_{\mathrm{d}}$ was the constant of the thermodynamic equilibrium, and $\mathrm{R}=8.314 \mathrm{~J} \cdot \mathrm{mol}^{-1} \cdot \mathrm{K}^{-1}$ was the ideal gas constant. T represented the absolute temperature.

The thermodynamic experimental data were listed in table 6 which under the condition of $\mathrm{T}=288.15 \mathrm{~K}, \mathrm{~T}=293.15$ $\mathrm{K}, \mathrm{T}=298.15 \mathrm{~K}, \mathrm{~T}=303.15 \mathrm{~K}$ and $\mathrm{T}=308.15 \mathrm{~K}$. the $\Delta H$ value and $\Delta S$ value for the sorption process were obtained by simulating the slope and intercept of the curves as shown in Fig. 3(d). The values of $\Delta G$ were regraded to describe the thermodynamic properties of the sorption process. The positive $\Delta S$ values and the positive $\Delta H$ values indicating that the adsorption reactive was an endothermic process with entropy increased, and under the condition of the increasing temperature the values of negative $\Delta G$ were decreased. It was demonstrated that higher temperature has positive effect on the spontaneous sorption behaver, and more active groups catch uranium ions by complexation reaction. This result superimposed revealing that the adsorption behaver was controlled by chemisorption.

\subsection{Desorption and reusability}

Regeneration-reusability is very important for economic value and environment friendly in practical application. desorption experiments of $\mathrm{U}(\mathrm{VI})$ were performed with 1 $\mathrm{mol} / \mathrm{L} \mathrm{Na}_{2} \mathrm{CO}_{3}$ solution, $1 \mathrm{~mol} / \mathrm{L} \mathrm{HCl}$ solution and $1 \mathrm{~mol} / \mathrm{L}$ $\mathrm{HNO}_{3}$ solution, As can be seen from Fig. 4(a), 1 mol/L $\mathrm{HNO}_{3}$ solution was best eluent for desorption of $\mathrm{U}(\mathrm{VI})$ on AO-HTC. The results were shown in Fig. 4(b), the sorption capacity of $\mathrm{U}(\mathrm{VI})$ decreased slightly from $231.8 \mathrm{mg} \cdot \mathrm{g}^{-1}$ to $220.2 \mathrm{mg}^{-1}$ after five consecutive sorption-desorption cycles, which indicates that the surface groups of material exhibits high structural stability in HTC, and revealing the AO-HTC presented excellent reusability that is great importance for the groundwater remediation of $\mathrm{U}(\mathrm{VI})$.

Table 5. Parameters for Langmuir, Freundlich isotherm models

\begin{tabular}{ccccccc}
\hline \multirow{2}{*}{ Absorbent } & \multicolumn{3}{c}{ Langmuir isotherm } & \multicolumn{3}{c}{ Freundlich isotherm } \\
\cline { 2 - 7 } & $\mathrm{K}_{\mathrm{I}}$ & $q_{m}\left({\left.\mathrm{mg} \cdot \mathrm{g}^{-1}\right)}^{-1}\right.$ & $R^{2}$ & $\mathrm{~K}_{\mathrm{F}}$ & $\mathrm{n}$ & $R^{2}$ \\
\hline HTC & 0.025 & 128.58 & 0.957 & 13.33 & 2.29 & 0.939 \\
AO-HTC & 0.048 & 244.11 & 0.991 & 22.01 & 1.80 & 0.933 \\
\hline
\end{tabular}

Table 6. Thermodynamic parameters of U(VI) adsorption on AO-HTC and HTC

\begin{tabular}{|c|c|c|c|c|c|c|c|}
\hline \multirow[b]{2}{*}{ Absorbent } & \multirow{2}{*}{$\begin{array}{c}\Delta H \\
\left(\mathrm{~kJ} \cdot \mathrm{mol}^{-1}\right)\end{array}$} & \multirow{2}{*}{$\begin{array}{c}\Delta S \\
\left(\mathrm{~J} \cdot \mathrm{mol}^{-1} \cdot \mathrm{K}^{-1}\right)\end{array}$} & \multicolumn{5}{|c|}{$\Delta G\left(\mathrm{~kJ} \cdot \mathrm{mol}^{-1}\right)$} \\
\hline & & & $\begin{array}{c}288.15 \\
(\mathrm{~K})\end{array}$ & $\begin{array}{c}293.15 \\
(\mathrm{~K})\end{array}$ & $\begin{array}{c}298.15 \\
(\mathrm{~K}) \\
\end{array}$ & $\begin{array}{c}303.15 \\
(\mathrm{~K})\end{array}$ & $\begin{array}{c}308.15 \\
(\mathrm{~K}) \\
\end{array}$ \\
\hline HTC & 25.39 & 143.04 & -15.82 & -16.54 & -17.25 & -17.97 & -18.68 \\
\hline AO-HTC & 18.04 & 128.29 & -18.92 & -19.56 & -20.21 & -20.85 & -21.49 \\
\hline
\end{tabular}



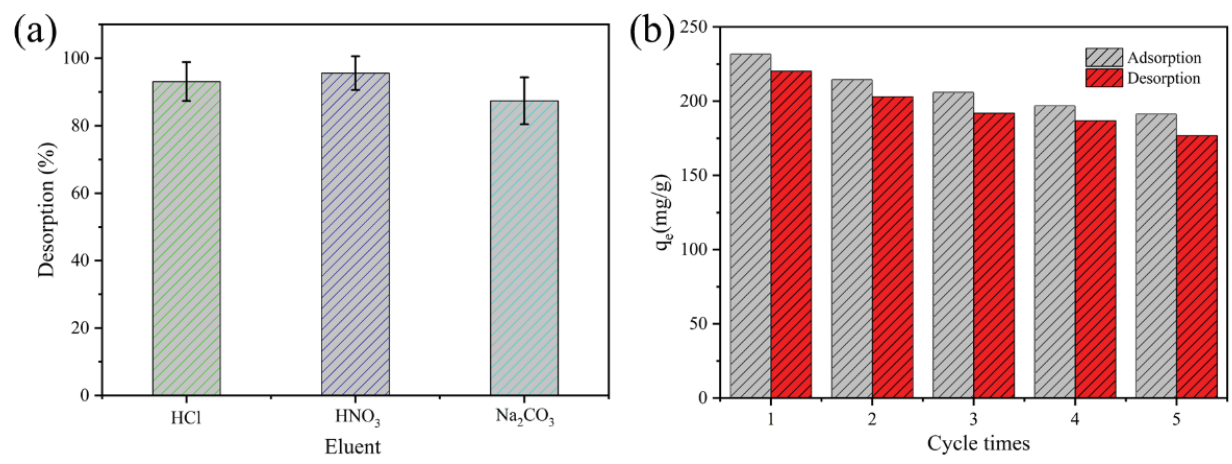

Figure 4. Desorption of uranium with various eluent (a), regenerated use of AO-HTC (b).

\subsection{Post-sorption characterization}

FT-IR and SEM were used to further observed the changes in the microstructure and morphology of the AO-HTC after adsorption of $U$ (VI). In the FT-IR spectrum of Fig. 5(a), the characteristic stretching vibration of $[\mathrm{O}=\mathrm{U}(\mathrm{VI})=\mathrm{O}]^{2+}$ at $919 \mathrm{~cm}^{-1}$ to $968 \mathrm{~cm}^{-1}$ was overlapped by the stretching vibration of $\mathrm{C}-\mathrm{O}$ or $\mathrm{N}-\mathrm{O}^{[43]}$. In addition, the characteristic peaks of other groups obviously displacements among the amidoxime, carboxylic and hydroxylic or amidogen groups $\left(766 \mathrm{~cm}^{-1}\right.$ to $1056 \mathrm{~cm}^{-1}, 1506 \mathrm{~cm}^{-1}$ to $1788 \mathrm{~cm}^{-1}, 3390 \mathrm{~cm}^{-1}$ to $3448 \mathrm{~cm}^{-1}$ ), which could be amidoxime and carboxylic groups banding with uranyl ion on the surface of AO-HTC, and reduced the band intensity of functional groups ${ }^{[44]}$. The SEM images confirmed that the morphology of AO-HTC was well preserved after adsorption (Fig. 5(b-c)), and the surface of AO-HTC showed abundant pores, which was helpful to improve the grafting rate of amidoxime groups on HTC. In Fig. 5(d), The SEM elemental mapping images further proves that the radionuclide was anchored onto the surface of AO-HTC during the adsorption process.
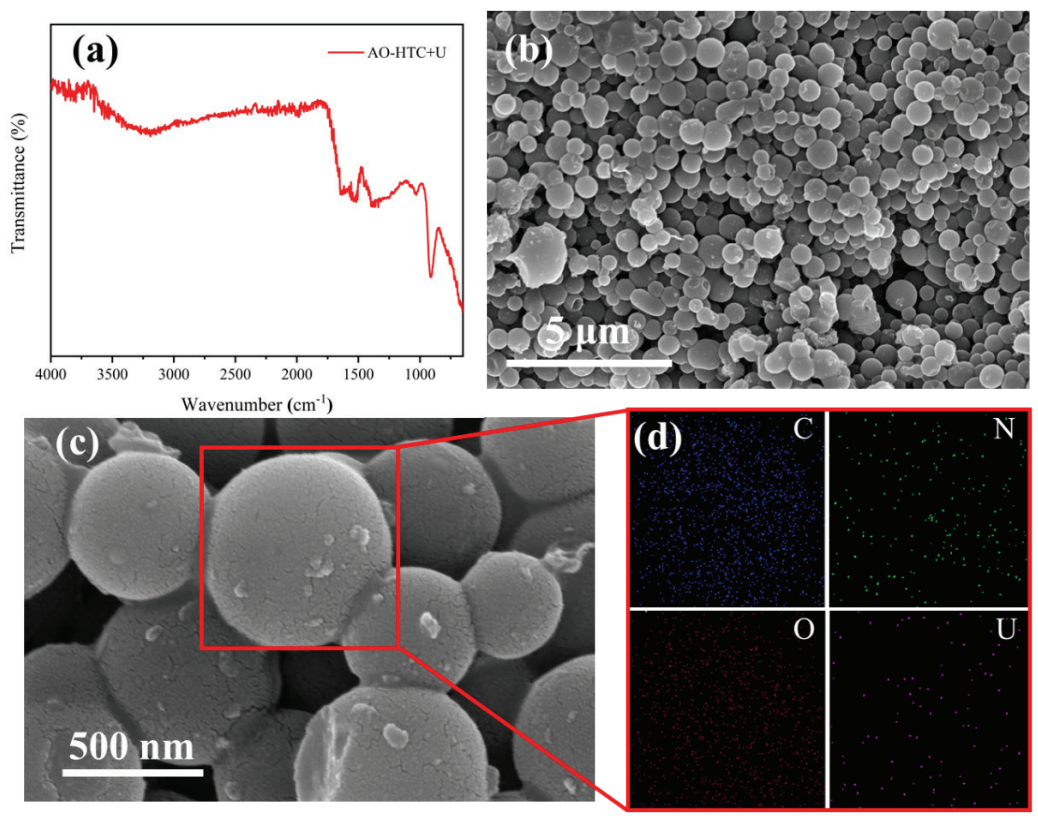

Figure 5. The FT-IR spectra (a), SEM images (b-c) and elemental mapping (d) of the post-sorption of U(VI) on AO-HTC.

\section{Conclusion}

In this study, a novel adsorbent is synthesized by amidoximefunctionalized HTC using a common, commercially available, inexpensive raw material and a simple, mild preparation process. It was characterized by SEM, FTIR, BET and Elemental analysis. The results of AOHTC adsorption of uranium showed that the adsorption was negatively correlated with $\mathrm{pH}$, total carbonic acid concentration, calcium ion concentration and humic acid concentration. The results of influencing factors such as contact time, initial uranium concentration and temperature indicate that the adsorption of $\mathrm{U}(\mathrm{VI})$ on AO-HTC is a $\mathrm{pH}$ dependent, endothermic, spontaneous and pseudo secondorder process. The AO-HTC adsorbent exhibited excellent reusability without significant changes in the adsorption capacity and structural stability after five cycles. The novel AO-HTC adsorbent has broad application prospects in uranium separation from radioactive groundwater and 
other related water sources.

Acknowledgments: This work was financially supported by the National Natural Science Foundation of China (21561002, 21866004, 21866003).

\section{References}

[1] B. Kornilovych, M. Wireman, S. Ubaldini, D. Guglietta, Y. Koshik, B. Caruso and I. Kovalchuk, Metals, 2018, 8,408

[2] A. A. H. Faisal and Z. A. Hmood, Desalination and Water Treatment, 2015, 53, 1377-1386.

[3] F. Obiri-Nyarko, S. J. Grajales-Mesa and G. Malina, Chemosphere, 2014, 111, 243-259.

[4] X. Liu, J. Sun, X. Xu, A. Alsaedi, T. Hayat and J. Li, Chem. Eng. J., 2019, 360, 941-950.

[5] M. Jimenez-Reyes and M. Solache-Rios, Water Air and Soil Pollution, 2018, 229.

[6] Z. B. Zhang, J. Liu, X. H. Cao, X. P. Luo, R. Hua, Y. Liu, X. F. Yu, L. K. He and Y. H. Liu, J. Hazard. Mater., 2015, 300, 633-642.

[7] X. Han, Y. Wang, X. Cao, Y. Dai, Y. Liu, Z. Dong, Z. Zhang and Y. Liu, Appl. Surf. Sci., 2019, 484, 1035-1040.

[8] J. Yang, M. Ge, Q. Jin, Z. Chen and Z. Guo, Chemosphere, 2019, 231, 405-414.

[9] H. Tu, T. Lan, G. Yuan, C. Zhao, J. Liu, F. Li, J. Yang, J. Liao, Y. Yang, D. Wang and N. Liu, Journal of Environmental Radioactivity, 2019, 197, 23-29.

[10] S. Lu, K. Zhu, H. Guo, H. Wang, N. Zhang, A. Alsaedi, T. Hayat, Y. Li and Y. Sun, Chem. Eng. J., 2019, 368, 598-605.

[11] D. K. Gupta, A. V. Voronina, V. S. Semenishchev and S. Chatterjee, in Green Adsorbents for Pollutant Removal: Innovative Materials, eds. G. Crini and E. Lichtfouse, 2018, vol. 19, pp. 377-396.

[12] X. Wang, S. Yu, Y. Wu, H. Pang, S. Yu, Z. Chen, J. Hou, A. Alsaedi, T. Hayat and S. Wang, Chem. Eng. J., 2018, 342, 321-330.

[13] C. Chen, K. Zhao, J. Shang, C. Liu, J. Wang, Z. Yan, K. Liu and W. Wu, Environ. Pollut., 2018, 240, 219-226.

[14] Y. Zou, X. Wang, F. Wu, S. Yu, Y. Hu, W. Song, Y. Liu, H. Wang, T. Hayat and X. Wang, Acs Sustainable Chemistry \& Engineering, 2017, 5, 1173-1185.

[15] P. Li, J. Wang, Y. Wang, J. Liang, B. He, D. Pan, Q. Fan and X. Wang, Chem. Eng. J., 2019, 365, 231-241.

[16] W. Li, Q. Liu, R. Chen, J. Yu, H. Zhang, J. Liu, R. Li, M. Zhang, P. Liu and J. Wang, Inorganic Chemistry Frontiers, 2018, 5, 1321-1328.

[17] H. Basu, S. Saha, M. V. Pimple and R. K. Singhal, Journal of Environmental Chemical Engineering, 2019, 7,103-110

[18] Z. Zeng, Y. Wei, L. Shen and D. Hua, Industrial \& Engineering Chemistry Research, 2015, 54, 8699-8705.

[19] S. H. Choi, M. S. Choi, Y. T. Park, K. P. Lee and H. D. Kang, Radiat. Phys. Chem., 2003, 67, 387-390.

[20] Y. Yuan, S. Zhao, J. Wen, D. Wang, X. Gu, L. Xu, X. Wang and N. Wang, Adv. Funct. Mater., 2019, 29,2

[21] Z. Zhang, Z. Dong, Y. Dai, S. Xiao, X. Cao, Y. Liu, W. Guo, M. Luo and Z. Le, RSC Adv., 2016, 6, 102462-102471.
[22] Z. Zhang, Z. Dong, X. Wang, D. Ying, F. Niu, X. Cao, Y. Wang, R. Hua, Y. Liu and X. Wang, Chem. Eng. J., 2018, 341, 208-217.

[23] M. Monier, D. A. Abdel-Latif and H. A. Mohammed, International Journal of Biological Macromolecules, 2015, 75, 354-363.

[24] X. Lu, S. He, D. Zhang, A. T. Reda, C. Liu, J. Feng and Z. Yang, RSC Adv., 2016, 6, 101087-101097.

[25] R. Coskun and C. Soykan, Journal of Applied Polymer Science, 2009, 112, 1798-1807.

[26] Y.-Q. Wang, Z.-B. Zhang, Y.-H. Liu, X.-H. Cao, Y.-T. Liu and Q. Li, Chem. Eng. J., 2012, 198, 246-253.

[27] Y. Liu, Q. Li, X. Cao, Y. Wang, X. Jiang, M. Li, M. Hua and Z. Zhang, Appl. Surf. Sci., 2013, 285, 258-266.

[28] Z.-p. Cheng, Y.-h. Liu, G.-x. Xiong, X.-p. Luo, X.-h. Cao, M. Li and Z.-b. Zhang, J. Radioanal. Nucl. Chem., 2015, 306, 365-375.

[29] A. Mellah, S. Chegrouche and M. Barkat, Journal of Colloid and Interface Science, 2006, 296, 434-441.

[30] C. Y. Xie, S. P. Jing, Y. Wang, X. Lin, H. L. Bao, C. Z. Guan, C. Jin and J. Q. Wang, Nucl. Sci. Tech., 2017, 28, 8.

[31] S. Duan, X. Xu, X. Liu, Y. Wang, T. Hayat, A. Alsaedi, Y. Meng and J. Li, Journal of Colloid and Interface Science, 2018, 513, 92-103.

[32] G. Tian, J. Geng, Y. Jin, C. Wang, S. Li, Z. Chen, H. Wang, Y. Zhao and S. Li, J. Hazard. Mater., 2011, 190, 442-450.

[33] Y.-H. Liu, Y.-Q. Wang, Z.-B. Zhang, X.-H. Cao, W.-B. Nie, Q. Li and R. Hua, Appl. Surf. Sci., 2013, 273, 68-74.

[34] A. S. Kar, A. Saha, A. Chandane, S. Kumar and B. S. Tomar, Radiochimica Acta, 2018, 106, 191-205.

[35] Y. Zhang, Y. Li, Y. Ning, D. Liu, P. Tang, Z. Yang, Y. Lu and X. Wang, Water Science and Technology, 2018, 77, 920930.

[36] J. Hui, Y. Wang, Y. Liu, X. Cao, Z. Zhang, Y. Dai and Y. Liu, J. Radioanal. Nucl. Chem., 2019, 319, 1251-1259.

[37] E. Prasetyo, Mineral Processing and Technology International Conference, 2018, 285,012011

[38] T. Lan, J. Liao, Y. Yang, Z. Chai, N. Liu and D. Wang, Environ. Sci. Technol., 2019, 53, 5102-5110.

[39] L. Liu, J. Liu, X. Liu, C. Dai, Z. Zhang, W. Song and Y. Chu, Journal of Environmental Radioactivity, 2019, 203, 117124.

[40] F. Meng, G. Yuan, S. L. Larson, J. H. Ballard, J. R. White, Z. Arslan and F. X. Han, International Journal of Environmental Research and Public Health, 2019, 16,9

[41] Y.-Q. Wang, Z.-b. Zhang, Q. Li and Y.-H. Liu, J. Radioanal. Nucl. Chem., 2012, 293, 231-239.

[42] Z. Zhang, Z. Dong, X. Wang, Y. Dai, X. Cao, Y. Wang, R. Hua, H. Feng, J. Chen, Y. Liu, B. Hu and X. Wang, Chem. Eng. J., 2019, 370, 1376-1387.

[43] S. Song, S. Zhang, S. Huang, R. Zhang, L. Yin, Y. Hu, T. Wen, L. Zhuang, B. Hu and X. Wang, Chem. Eng. J., 2019, 355, 697-709.

[44] X. Yang, J. Li, J. Liu, Y. Tian, B. Li, K. Cao, S. Liu, M. Hou, S. Li and L. Ma, J. Mater. Chem. A, 2014, 2, 1550-1559. 